\title{
Physical Health Examinations in a Psychiatric Setting: The Interactions between Medical Doctor and Patients
}

\section{Anne Mette Juul Andersen ${ }^{*}$, Henriette Laugesen ${ }^{1}$, Bodil Margrethe Nielsen², Tine Mechlenborg Kristiansen ${ }^{3}$}

\author{
${ }^{1}$ Department of Medicine and Health Technology, Aalborg University, Aalborg, Denmark \\ ${ }^{2}$ Department of Sociology and Social Work, Aalborg University, Aalborg, Denmark \\ ${ }^{3}$ Kong Chr. X’s Hospital of Rheumatic Diseases, Graasten, Denmark \\ Email: ^annemetteja@gmail.com, henriettelaugesen@gmail.com,bmn@socsci.aau.dk, tmechlenborgkristiansen@gigtforeningen.dk
}

How to cite this paper: Andersen, A. M. J., Laugesen, H., Nielsen, B. M., \& Kristiansen, T. M. (2018). Physical Health Examinations in a Psychiatric Setting: The Interactions between Medical Doctor and Patients. $A d$ vances in Applied Sociology, 8, 76-93. https://doi.org/10.4236/aasoci.2018.81005

Received: December 13, 2017

Accepted: January 28, 2018

Published: January 31, 2018

Copyright $\odot 2018$ by authors and Scientific Research Publishing Inc. This work is licensed under the Creative Commons Attribution International License (CC BY 4.0).

http://creativecommons.org/licenses/by/4.0/

\begin{abstract}
The purpose of this article is to shed light on the possible stigmatization during a physical health examination in a psychiatric setting and explore the medical doctor and patients' perceptions of such an integrated care model. This is a qualitative case study using semi-structured interviews and observations. Empirical findings are analyzed using the theory of stigma in order to explore the role of stigmatization in an integrated care setting. The analysis finds three main themes: 1) The advantages of a safe and familiar setting, 2) To be treated as a human being-not an illness, 3) Interpersonal communication with mutual understanding can reduce stigmatization. The results show that stigmatization does occur at some points. However, both patients and the medical doctor think that the integrated care setting contributes to a successful physical health examination. This is due to the location as well as interpersonal aspects.
\end{abstract}

\section{Keywords}

Mental Illness, Physical Health Care, Stigma, Integrated Health Care, Interpersonal Interaction

\section{Introduction}

People with mental illness have a significantly lower life-expectancy compared to the general population (see e.g. Nordentoft et al., 2013). This is largely due to physical diseases such as cardiovascular disease, cancer, diabetes and respiratory diseases (Lawrence, Hancock, \& Kisely, 2013). The physical morbidity among 
people with mental illness can partly be attributed to their reduced access to physical health care (Lawrence \& Kisely, 2010). Empirical studies have shown how people with mental illness experience stigma when interacting with health care professionals (Borba et al., 2012; Roberts \& Bailey, 2011). They experience how the treatment system regards them with a non-positive attitude, and they feel that they do not necessarily receive the medical care which they need. In addition, mentally ill people often feel misunderstood by the health professionals and state that they are condescending and lack solidarity and empathy (Blikkenberg \& Vendsborg, 2011; Jacobsen, Martin, Andersen, Christensen, \& Bengtsson, 2010). Such stigmatization is very relevant to be aware of since it affects how people with mental illness seek and adhere to treatment (De Hert et al., 2011). Taken together, this knowledge emphasizes the importance of focusing on the patient-health professional interactions but it also points to the need for exploring integrated care models that could potentially help reduce stigmatizing of people with mental illness and thereby enhance chances of treatment adherence. Several integrated care models that seek to improve the physical health of people with mental illness have been implemented (see e.g. Muntingh et al., 2009; Sowers, Arbuckle, \& Shoyinka, 2016). Such integrated care can detect a higher number of somatic health problems compared to non-integrated models (Tranter, Irvine, \& Collins, 2012; van Hasselt, Thier, van Rijswijk, \& Loonen, 2014). Yet, there is still disagreement about the best setting and way to deliver appropriate integrated care. Wright et al. emphasize that a complex solution to a complex problem is required (2006). In a number of qualitative studies, the health professional as well as people with mental illness' perspectives regarding integrated care models are investigated. Some find it should be located in the primary care sector and be carried out by the general practitioner (Pitman, Osborn, Wright, Nazareth, \& King, 2011), whereas others argue a dedicated clinic for people with mental illness is a better solution as the patients feel more comfortable in such a setting (Wright et al., 2006). Such a result indicates a possible underlying problem of perceived stigmatization in some integrated care models. Overall, health professionals as well as people with mental illness agree on the importance of a physical health examination (Shuel, White, Jones, \& Grey, 2010). People with mental illness state that they are happy to be invited to a physical health examination, and it is important for them to feel understood as a patient with both mental and physical health problems (Hardy, Deane, \& Gray, 2012). The authors have not been able to identify any studies regarding integrated care models whose main purpose has been to explore the interaction in terms of stigmatization. The purpose of the study was to contribute to this knowledge gap by exploring the interaction between the medical doctor and patient during a physical health examination in a psychiatric outpatient clinic in Denmark in order to shed light on the possible stigmatization that can arise in such an integrated care model.

\section{Theoretical Perspective}

Stigma is created and spread through communication (Smith, 2007; Smith et al., 2016). Different scholars have dealt with stigma and it is related to different as- 
sumptions and definitions. In this article we use Goffman's definition (1963: 3) of stigma: "(..) an attribute that is deeply discrediting”. Goffman is interested in the interaction between human beings, and he emphasizes how both verbal and non-verbal communication is essential during social face-to-face encounters (Goffman, 2005). In the interaction with others, people tend, unintentionally, to categorize on the basis of attributes. These categories transform into normative expectations whereby the individual is given a "virtual social identity" that might differ from the qualities and attributes the person possesses that is the "actual social identity". On the basis of the perceived attributes, discrimination of various kinds is applied and a stigma theory is constructed. According to Goffman, three types of stigma exist: "the abominations of the body", which refers to physical deformities, "tribal stigma", which is stigmatization due to race, religion and nation and "blemished individual character" such as addiction, unemployment and mental illness. When a person has one of these discrediting attributes he or she is perceived as a reduced and tainted individual rather than a whole human being (Goffman, 1963: 3-5). Goffman categorizes people into three different groups: "the own", "the wise" and "the normal". The own are the people who share a stigma, for example having a mental illness (1963: 30), the wise are sympathetic others who adopt and share the stigmatized' standpoint (1963: 19) and the normal are those who do not depart negatively from normative expectations (Goffman, 1963; Smith, Quesnell, \& Zhu, 2016).

Link and Phelan have expanded Goffman's concept, and have stated that stigma only exist because of power differences in social interactions. They explain that in order to stigmatize, one must possess social, cultural, economic and/or political power. By stigmatizing, people with undesirable characteristics are positioned in a separate category in order to make a distinction between "us" and "them" (Link \& Phelan, 2001: 367). This expansion is relevant to include, as there is a hierarchy and thus power differences in the doctor-patient relationship.

\section{Design and Methods}

\subsection{Design}

The current study was guided by a qualitative design. As the health examination in a psychiatric setting performed by a general practitioner is unique in a Danish health care setting, it is a deviant case study (Flyvbjerg, 2011). The study was positioned within social interactionism, which means that meaning is a social product created and modified through interaction (Blumer, 1969). This design and epistemological position allowed us to study the interaction during a physical health examination and the participants' subjective perspectives.

\section{The Empirical Case and Recruitment}

In Denmark, multiple changes in health policies have been made in order to meet the disparity in health care for people with mental illness. Initiatives have been implemented in national as well as regional contexts (Ministeriet for 
Sundhed og Forebyggelse, 2014; Region Hovedstaden, 2015; Sikker Psykiatri, 2016; Sundhedsstyrelsen, 2009). One of these initiatives is located in the Capital Region of Denmark. The physical health examination is an initiative performed by a medical doctor in psychiatric outpatient clinics. The physical health examination aims to screen and identify undetected physical diseases and thereby improve the patients' health. The regional mental health staff offer all patients to participate in the health examination.

The patients were recruited through the medical doctor and pragmatically selected, as it was those whom had their physical health examinations completed on the predetermined dates the observations were scheduled (Creswell, 2013). Furthermore, some of the observed patients were selected purposively for interviews in order to get a maximum variation among the informants and thereby yield the most information-rich data (Yin, 2016). The patients represented both genders, were 19 - 62 years old and diagnosed with schizophrenia, anxiety, depression or schizotypal disorder. The patients lived in different districts within the Capital Region of Denmark and reflected a wide scope of socio-economic status. The medical doctor was a health professional with training in general medicine, who had several years of experience working with psychiatric patients and performing physical health examinations. Thus, he was a general practitioner who entered a psychiatric setting in order to improve the patients' physical health.

\subsection{Methods}

In this case study, data was gathered using multiple sources of evidence in order to provide an in-depth understanding of a real life phenomenon (Yin, 2009). The data was collected between March and May 2016 by A.M.J.A and H.L.

Observations were employed in order to shed light on verbal as well as non-verbal interaction during the physical health examination and how the interaction was influenced by the social context. 10 physical health examinations were observed and each lasted approximately 25 minutes. During the observations field notes were jotted into a notebook and these were written up immediately after each observation. The notes were descriptive as well as analytical (Bernard, 2011).

In addition to the observations, 9 short interviews, circa 5 minutes, were carried out with the patients immediately after the physical health examination ended in order to get their immediate reaction and get their consent to participate in a potential additional semi-structured interview. One patient chose not to participate in the short interview due to a high level of social paranoia. Four patients and the medical doctor participated in a semi-structured interview to get an understanding of their subjective experience of the physical health examination, including the topics, interaction and location. These were held $1-3$ weeks after the observations. The patients were interviewed in their own homes whereas the interview with the medical doctor was carried out at one of the psy- 
chiatric clinics. The semi-structured interviews lasted between 20-40 minutes. All interviews were audiotaped and subsequently transcribed verbatim. All quotations have been translated from Danish into English.

\section{Ethics}

The study was conducted in accordance with established rules and codes within research ethics (Flick, 2009; Israel, 2015). All participants' interest has been taken into account and protected throughout the research process.

Prospective participants were first introduced to the study by the medical doctor before their physical health examination and were informed about the voluntary nature of the study. Afterwards each participant was addressed by one of the first two authors (A.M.J.A or H.L) where they were further informed of their rights, the purpose of the study, that they could withdraw from the study at any time and that data would be kept confidential and handled anonymously. Each participant gave oral and written consent.

\section{Data Analysis}

Data was analyzed by two of the authors (A.M.J.A or H.L) using a grounded theory coding strategy formulated by Charmaz (2001), which divides the coding process into two phases; initial and selective coding. The movement from initial to selective coding occurred by identifying common coding patterns across the different field notes and interview transcripts, and thereby forming more abstract and general codes (Charmaz, 2001). The data was processed using an abductive method, which is positioned between inductive and deductive reasoning (Bryant \& Charmaz, 2014). The initial phase was empirically driven and later throughout the selective coding and analysis process, the theoretical perspective "stigma" was used as a sensitizing concept, to form a point of reference and guidance when approaching the empirical data (Coffey \& Atkinson, 1996).

The patients and medical doctor were not asked directly about stigmatization, but instead we focused on the interaction, how they experienced the health examination, which elements during the physical health examination they emphasized as important, if they contacted their own general practitioner and what they thought about mental as well as physical health. The medical doctor was asked about the purpose of the physical health examination, roles and conduct during the examination and possible pitfalls. Additionally, verbal as well as non-verbal communication between the medical doctor and the patiens was analyzed. It was evident in the data material that stigmatization was a subject the patients attributed great significance, which is why it is used as a sensitizing concept.

\section{Results}

The data was analyzed and interpreted using the theoretical concept of stigma. This resulted in three main themes: 1) To be treated as a human being-not an illness, 2) The advantages of a safe and familiar setting, 3) Interpersonal com- 
munication with mutual understanding can reduce stigmatization. In all these themes, it is clear how the interpersonal relation is a prominent factor, which is reflected in how the themes are closely intertwined and at some points overlapping.

\subsection{To be Treated as a Human Being-Not an Illness}

The patients and the medical doctor found that it could be a challenge for a person with mental illness to be accepted and understood in the somatic health care system. This was an important issue given the fact that the patients ascribed their physical health great importance and several of the patients stressed that physical and mental health are interconnected and cannot be separated.

Three out of four patients that participated in the semi-structured interviews told that they experienced stigmatization during their interaction with the somatic health care system due to their mental illness. In contrast, none of the participants stated that they felt stigmatized during the physical health examination with the medical doctor. This could be a result of the patients' fear of expressing a feeling of being stigmatized due to previous experiences with discredit or it can be attributed to the medical doctor's awareness of stigmatization in the health care system. The medical doctor explained his experience with psychiatric patients at a former workplace:

"I remember many patients from the clinic (his earlier workplace), who were physically and psychiatrically stigmatized, coming into my clinic and did not know what they really wanted. And I didn't either. So, the consultation ended rather quickly" [Interview, MD].

Thus, the medical doctor was aware that the group was stigmatized in the society. It could be argued that because the medical doctor paid attention to stigmatization, it is likely that he did not make assumptions based on their mental illness, but he saw their actual social identity (Goffman, 1963: 2).

The participants all emphasized that the medical doctor was thorough and observant, which they highly appreciated. When the patients were asked about how they liked the health examination they explained:

"(...) he was thorough, and he took me seriously and he took my answers seriously. And (he took) my question serious, yeah (...). He asked about many symptoms, so to speak. So, I could sense that he ranged very widely as if to check whether it could be other things than anxiety, right" [Interview, pt. 1].

"So, he was not like: 'you have anxiety and ...'. He took me seriously, so he was fantastic (...). Well, he took it seriously and examined me for the physical illness to see if there was something (wrong based on the symptoms) $I$ described, right' [Short interview, pt. 6].

It was important for the patients to be taken seriously and acknowledged as an ordinary patient. In the perspective of Goffman, the patients' satisfaction could be related to their self-understanding, because the stigmatized individual defines 
himself or herself as both a normal human being and as one being potentially stigmatized (Goffman, 1963).

The medical doctor did not use a stigma theory and misattributed their physical symptoms to their mental illness (Goffman, 1963). In contrast, he acknowledged and accepted the patients as whole human beings by his use of physical reasoning and thus provided them with the same possibilities to receive a thorough physical health examination as the rest of the population.

In the extract below, the medical doctor explained how he sought to involve the patients in the examination. He wanted to give them the possibility to tell about the problems they experienced because he aimed to make the patients feel that their perspectives were being heard and make it clear that they had an influence on the examination:

"Some of the patients are pretty good at figuring out what the problem is.

And the things they present are often among the first in my manuscript, so these will be given priority in the medical note I send to their general practitioner, because normally they are quite accurate regarding their own health" [Interview, MD].

Here it is demonstrated how the medical doctor sought to avoid stigmatization by acknowledging and recognizing the patients' possible concerns related to their physical health and took it seriously by giving them priority during the physical health examination. However, in some cases, the medical doctor failed to recognize the patients' concerns. In the beginning of a health examination the medical doctor asked about the patient's diet, but he did not react to the patient's answers. Afterwards, the patient mentioned concerns regarding his weight and nutritional intake as showed below:

"(The patient) mentions the fried chicken again. The fried chicken is obviously important to him and it may indicate that he wants to talk about a dietary change" [Field note, pt. 2].

Despite the patient repeatedly returned to the topic, the medical doctor did not accept the patient's input and agenda. This can be due to the medical doctor's manuscript, which sets a strict agenda. Moreover, the medical doctor did not always succeed in his desire to include the patients by asking them if they had any specific questions they wished to address. This illustrates, that despite the medical doctor's intentions and on-going effort to avoid stigmatization, it can still occur.

\subsection{The Advantages of a Safe and Familiar Setting}

Both the medical doctor and some patients expressed how they experienced great advantages of the physical health examination's placement in a psychiatric context. These advantages were based on previous experiences regarding the multiple difficulties the psychiatric patients encounter when entering the physical health care system. The medical doctor explained how the integrated setup was supposed to create a shortcut into the health care system and to minimize 
the barriers these patients experienced:

“(...) trying to make it easier for the patients to get into the health care system. Paving the way for future contacts, give them easier access to health care on equal terms with others' [Interview, MD].

The fact that the medical doctor emphasized: "on equal terms" indicated his acknowledgement of the fact that the somatic health care system cannot necessarily accommodate and understand patients with mental illness. The patients often suggested that they simply felt safer in a psychiatric setting:

"It was just not quite as safe to enter the physical system as a psychiatric patient, right, compared to entering a psychiatric clinic, so ... It is just safer because people (employed at the psychiatric clinic) know what they are dealing with" [Interview, pt. 1].

This feeling of safety during the physical health examination seemed to be related to the patients' preliminary assumptions related to the psychiatric context and experiences of how the medical doctor handled the patients during the health examination. The medical doctor presented himself as a doctor with expertise in general medicine, and he did not claim to the patients that he had any specialized knowledge of psychiatry. Nevertheless, the patients assumed that the medical doctor would understand them as a patient who had a psychiatric as well as a somatic health problem due to the psychiatric context. One patient expressed it the following way:

"It's because that. Well it's because he probably knows something about psychiatry, since he is there, right? So he has something, anyway. Maybe (he has) a little more knowledge about psychiatry than others" [Interview, pt. 1].

Another patient spoke of a similar understanding:

"He (the medical doctor) seemed like he knew what he was doing-knew how to handle someone like me" [Interview, pt. 6].

The feeling of safety could be related to the expectations and previous experiences the patients have in psychiatric and somatic health care settings. The patients further explained that the medical doctor made them feel "relaxed" [pt. 3, $6,9]$ and they stated that he was "nice", "pleasant", "calm" and "sweet" [pt. 1, 3, $7,9,10]$ when asked about how they experienced the health examination. One patient described it:

"Well, he was nice ... Nice. How are people nice? You are also nice, right. He is nice, sweet and kind. Like, talks to me and such, rather than ignore me, and ... (He) thought of my health, actually" [Interview, pt. 10].

Thus, it seemed that it is not only the psychiatric setting in which the physical health examination was carried out that mattered. Evidently, the interpersonal aspects during the health examination were also important to the patients and their statements clearly indicated how they were often overlooked and not taken seriously in the somatic health care system. To be present was a deliberate choice and the medical doctor described that it was important in order to do his job well: 
"Well it's that you are present, present in the consultations and react. (That I) do not get so much routine in doing this that the individual patient becomes indifferent" [Interview, MD].

This illustrates that it was important for the medical doctor to not just complete a screening, but actually engage and immerse himself in the health examination. In the perspective of Goffman, having the physical health examination located in a psychiatric setting created a safe and well-known environment, where the patients did not have to adjust their behaviour in order to conceal their blemished individual character (Goffman, 1963).

\subsection{Interpersonal Communication with Mutual Understanding Can Reduce Stigmatization}

In Goffman's notion of the interaction ritual, verbal as well as non-verbal communications are key elements (Goffman, 2005). During the interaction, the medical doctor paid attention to both. In the interview, he explained that he tried to reflect on how to ask questions, and which words he should use in order to get as comprehensive answers as possible when he screened for physical problems:

"Yes, well I m trying to meet people where they are. I try not to let the length of my education affect the way we talk. I try to use words similar to those you would use when you talk with your friends about your health. Yes, yes, I try to make sure they do not have the feeling that it is an authority they are facing. $1 \mathrm{~m}$ trying to say it's not. Then it feels easier to talk' [Interview, MD].

The medical doctor used a deliberate communication strategy to get the best possible outcome. He was aware of the patients and their vocabulary. He tried not to use medical terms and considered how to ensure mutual understanding. During the observations, it was clear how he tried to relate his questions to everyday tasks:

"The patient says that he is not able to walk to the fifth floor when he (the medical doctor) asks, but the patient points out that it is not important as he never needs to go higher than the first floor. '1. floor is sufficient'. He explains that he would not be able to walk to fifth (floor) without taking breaks when the doctor asks specifically about the patient's ability to do this" [Field note, pt. 2].

Thus, when the medical doctor wanted to know about the patient's fitness level he asked about the ability to walk up the stairs without getting exhausted. Hereby, he made linguistic adaptions, which is a strategy he applied throughout the health examinations. However, in the analysis a discrepancy in the medical doctor's linguistic adaptions appeared. When the questions were implemented as a part of his manuscript, the medical doctor ensured mutual understanding. However, his professional medical vocabulary dominated, when he asked questions not included in the manuscript. The citation below is from an examination where a patient and his mother talk about overweight with the medical doctor:

"The doctor continues: 'cholesterol, and I think that is really good. The patient does not say anything. The medical doctor goes into a straightforward 
technical explanation: 'if you look at the distribution of his cholesterol, he does not have much HDL and little more triglycerides than what is good"' [Field note, pt. 9].

The medical doctor shifts his focus from the patient to the patient's mother and furthermore, his explanations are very technical. Consequently, the medical doctor did not always manage to avoid using medical explanations and ensure mutual understanding. The medical doctor's efforts to make linguistic adaption and the fact that he stated he did not want to be perceived as an authority illustrates how the medical doctor sought to avoid a separation between us and them, as it is the power differences that allows stigmatization to unfold (Link \& Phelan, 2001). However, as this only works then the medical doctor followed his manuscript he did not always succeed in minimizing the power differences and stigma (Goffman, 1963; Link \& Phelan, 2001).

Another linguistic strategy the medical doctor used was to continuously endeavour to defuse the situation in order to minimize apprehension among the patients. He was aware that his manuscript resulted in a strict agenda with many questions that could make the patients nervous and afraid of possible diseases:

"And there are situations when the doctor (doctors in general) says it, then you (as the patient) automatic say: 'shit, now $1 \mathrm{~m}$ sick', right. But that is not the point of the questions. We are talking to find out whether the organ system works well. Sometimes I can feel that now I must defuse, so they do not think its cancer-this is not a sign of cancer. Thereby, I try not to destroy their week because they have been here" [Interview, MD].

This was also seen during the observations:

"He sums up the conversation, and explains that depression can result in some cognitive problems, but that does not mean you are sick. He explains that it (the patient has problems with anxiety when she is alone) is related to the mental illness, and that it can take a year after she is declared healthy before it gets better" [Field note, pt. 8].

One patient expressed her gratitude towards the medical doctor's defusing approach the following way:

"I thought he was really... He listened and he took it all to heart and then. Subsequently, he explained how ... Why he did not suspect any dangerous things, such as cancer or ... And why he is also confident that it could be some other things" [Short interview, pt. 6].

The patients appreciated that the medical doctor took his time to listen and explain during the physical health examination. Thus, the medical doctor acted like the wise because he acted sympathetically towards a stigmatized group and did not devaluate them (Goffman, 1963; Smith et al., 2016).

During the observations, it became clear that the medical doctor's non-verbal communication to a large extent was consistent with his verbal communication:

"The doctor is leaning forward over the table and is constantly trying to make eye contact with the patient, who is repeatedly looking down at the ground or at 
his hands in his lap" [Field note, pt. 2].

Hence, the medical doctor used eye contact to show the patient that he was focused and kept his full attention on the individual patient. On the other hand, seen from the patient's perspective, the quote could also indicate that the patient did not feel equal and comfortable in a setting where everybody is sitting down around a table. According to Goffman, stigmatized persons can be insecure in the contact with others due to the fear of disrespect, being assessed and defined in terms of their stigma (Goffman, 1963).

Furthermore, non-verbal communication was used to achieve mutual understanding between the medical doctor and the patients. This was illustrated in the following excerpt from a field note, which refers to pain-related acid reflux:

"The patient hesitates and says nothing, tilts her hand. Maybe it means'sometimes', or it can be a signal that she is not quite sure what the doctor is talking about. The doctor takes his own hand up to the sternum to illustrate what he is talking about. She mirrors his body language. Now she says 'sometimes'" [Field notes, pt. 5].

Thus, the medical doctor used his own body to demonstrate what he was talking about. It was evident that the non-verbal communication created a greater degree of understanding between the parties. Thereby, he used the verbal and non-verbal language as a way to minimize stigma instead of using it to devaluate people with mental illness (Smith et al., 2016).

\section{Discussion}

In this deviant case study, viewed in the perspective of symbolic interactionism, three different themes appeared. The first theme showed that the patients' perception of the physical health examination was greatly influenced by the medical doctor's personal attributes and the fact that the medical doctor accepted them as patients with a need for a thorough physical health examination. The second theme illustrated how the location provided a safe setting where the patient's felt they did not need to conceal their mental illness. In the third theme, we demonstrated that the interpersonal communication between the medical doctor and the patients could be an important strategy to minimize the perceived feeling of stigmatization during the health examination. These results will be discussed in the following.

When the patients were asked about how they experienced the health examination, they emphasized the medical doctor's personal attributes and how much they liked him. The patients all emphasized that they felt heard and that the medical doctor cared about their physical health and well-being. Evidently, this is not uncommon. To like the health professional and feel the person listens and cares are all factors that facilitate good health care (Bellamy et al., 2016; Lester, Tritter, \& Sorohan, 2005), and negative experiences can in turn disempower the patients (Ewart, Bocking, Happell, Platania-Phung, \& Stanton, 2016). A positive relationship can in fact be an entry point into the health care system because the 
patients will be more likely to trust other health professionals they are referred to by a health care provider they trust and feel comfortable with (Borba et al., 2012).

The medical doctor wanted to include the patients and recognized their ability to point out their own physical health problems. He took their mental illness into account, but did not stigmatize and let it overshadow the physical health screening and thereby he generally avoided diagnostic overshadowing (Thornicroft, Rose, \& Kassam, 2007). The medical doctor used humanistic principals, which include: “(...) respect, listening, acknowledging the person's concerns, engaging with the client as she or he is, giving emotional support, aiming to understand the person's situation, working with existing strengths" (Horsfall, Cleary, \& Hunt, 2010: 453). Such an approach puts the whole person in the centre and this can minimize stigma (Van Den Tillaart, Kurtz, \& Cash, 2009). Thus, it is not necessarily only medical and practical factors that are important in an integrated care setting, but the way the patients feel treated is a facilitating factor to receiving further health care.

The results of this study illustrate the patients' appreciation of getting a thorough physical health examination in a psychiatric outpatient clinic where they were being taken seriously and felt safe. The patients in this study experienced their mental and physical health as interrelated and both were of great concern for the patients. However, often people with mental illness do not get the necessary physical treatment and there is a risk of these patients to fall in between two health care systems (Mainz, Sloth, \& Kjølbye, 2014; Mitchell, Malone, \& Doebbeling, 2009). Thus, the constructions of many Western health care systems conflicts with the patients' desires for holistic care, which suggests that placing a physical health examination in a psychiatric setting, could be highly beneficial. This is in accordance with results from other studies pointing to solutions such as co-location and liaise between psychiatric and physical health care because it produces better outcomes (See e.g. Bellamy et al., 2016; Lawrence \& Kisely, 2010).

Our results demonstrated how the location in a psychiatric setting generated a safe environment where the patients felt they were understood and not stigmatized due to their mental illness. The absence of stigmatizing behaviour from the health professionals is of great importance as it is perceived a barrier for people with mental illness to seek treatment (Wahl, 2012). Thus, the fact that our results show how the patients did not feel stigmatized during the physical health examination could have a positive effect on their further health seeking behaviour. However, the medical doctor's aspiration to make the physical health examination a shortcut into the health care system is dependent on the patients' further experiences in the health care system. This emphasizes that it is essential to not only focus on stigmatization in the mental health care system, but also on stigmatization of people with mental illness in the somatic health care system. Accordingly, to integrate a physical health examination in a psychiatric setting can be essential to ensure better health for people with mental illness. However, the 
health examination will not have any effect, if the patients do not get further examination and treatment. As other studies have pointed out - what really matters is to be sure that someone is taking the responsibility for the patients' physical health, and it must be clear who is doing what, when and where (Maj, 2009; Robson \& Gray, 2007).

At the moment, the medical doctor's responsibility is limited to completing the physical health examination and on the basis of his findings, to send a medical note to the patients' general practitioners. The general practitioner is not required to take initiatives upon this and instead it leaves the full responsibility on the patients. Thus, if the patients do not feel comfortable with their general practitioner, do not have the necessary resources or forget to seek further treatment, the physical health examination will only result in increased diagnoses, and not improved health and well-being. This is a serious pitfall of the health examination, seeing that previous research shows how only one third of patients seek out their general practitioner for the recommended further examination (Kølbæk, Schiöth, Aagaard, \& Munk-Jørgensen, 2014). Therefore, it can be argued that there is an imposing need for integrating the physical health examination in a psychiatric setting with the general practitioners' work. The psychiatric sector should prioritize bridging the gap by improving the collaboration using for example verbal encouragement and reminders (Vreeland, 2007).

The results illustrated that the medical doctor was aware of how he communicated verbally and it was consistent with his non-verbal communication. It is important that there is consistency between these elements because inconsistency can be perceived as 'lack of genuineness' (Hospital et al., 1995). Even though non-verbal cues are given little attention, it is especially important as it affects the patients satisfaction and the examinations success (Silverman \& Kinnersley, 2010). At some points, a gap between the medical doctor's ideal and how he actually acted during the health examination appeared. The medical doctor had some clear ideals regarding for example questioning techniques, but these did not always coincide with the reality. This emphasizes that despite good intentions it can be difficult to ensure a non-stigmatizing interaction. Thus, it can be argued that awareness on communication should be an ongoing effort. Communication skills, verbal as well as non-verbal, are undeniably an important factor to avoiding stigmatization because it is during the social interaction that stigma is created (Goffman, 1963; Smith et al., 2016). Furthermore, communication skills can influence the patients' degree of compliance and thus the health outcomes (Ammentorp, Sabroe, Kofoed, \& Mainz, 2009; Hassan, Mccabe, \& Priebe, 2007). This stresses, that it is important to incorporate communication strategies with special focus on avoiding stigmatization when developing and performing physical health examinations for people with mental illness.

As the research design and epistemological position in this study imply, the researcher influences the social situations in which the empirical material is si- 
tuated (Mik-Meyer \& Järvinen 2005; Crotty, 1998), and must be taken into consideration. Our presence during the health examination might have affected the way the medical doctor and patients interacted. Furthermore, because meaning is constructed and reconstructed continuously, the interview with the medical doctor might have affected the five subsequent health examinations, because he reflected about how he should act, and not how he actually did perform the health examinations. The patients were informed about the two authors' (A.M.J.A and H.L's) role and their anonymity. Nevertheless, the patients might not have felt safe to express negative views because they may have feared for the implications. However, the interaction during the health examination was consistent with the patient's statements during the short as well as semi-structured interviews. This indicates that the patients felt free to express their subjective opinions.

\section{Conclusion}

This study has successfully contributed with valuable knowledge regarding the interaction between the patients and medical doctor in an integrated care setting. It shows how the interaction was characterized by being a continuum between respect, recognition and stigmatization.

Stigma can have negative implication for people with mental illness' physical health, if the patients' physical health problems are only ascribed their mental health status. Furthermore, patients with mental illness experience mental and physical health as interrelated. Thus, it is important to ensure access to a comprehensive physical health examination.

The patients did not feel stigmatized but accepted as whole human beings, with mental and physical health problems, due to the location as well as the interpersonal interaction with the medical doctor. However, stigma did occur despite the medical doctor's effort see the patient's actual social identity. The results stress the importance of continually paying attention to and training non-stigmatizing communication, including using language that facilitates mutual understanding. When patients feel accepted and understood, there is a higher chance that they feel comfortable seeking out further treatment. Therefore, an integrated care model where physical health is examined in a psychiatric setting may facilitate more successful treatment. Consequently, integrated care could be an important approach to minimize patients' perceived stigmatization and inequality in health.

Currently, there is a lack of explorative studies that investigate how to ensure the patients receive further treatment, so the responsibility not only lies with the patient. Due to the size of the study, further research should investigate the relation between interpersonal interaction in integrated care and stigmatization to confirm the generalisability of the results. This knowledge is important in order to update health care policies and explore the possible advantage of integrated care regarding perceived stigmatization. 


\section{Acknowledgements}

The authors would like to thank the medical doctor and all patients that participated in this study.

\section{References}

Ammentorp, J., Sabroe, S., Kofoed, P. E., \& Mainz, J. (2009). Effects of a Communication Course for Clinicians on Parents' Perception of Care-A Randomized Controlled Trial. Scandinavian Journal of Caring Science, 23, 506-517. https://doi.org/10.1111/j.1471-6712.2008.00653.x

Bellamy, C. D. H., Flanagan, E., Costa, M., O’Connell-Bonarrigo, M., Tana Le, T., Guy, K., \& Steiner, J. L. (2016). Barriers and Facilitators of Healthcare for People with Mental Illness: Why Integrated Patient Centered Healthcare Is Necessary. Issues in Mental Health Nursing, 37, 421-428. https://doi.org/10.3109/01612840.2016.1162882

Bernard, H. R. (2011). Research Methods in Anthropology Qualitative and Quantitative Approaches (5th ed.). Blue Ridge Summit: AltaMira Press.

Blikkenberg, S., \& Vendsborg, P. (2011). Oplevelse af Fordomme Og Diskriminering. In P. Vendsbo, S. Blikkenberg, K. Kistrup, A. Lindhart, \& M. Nordentoft (Eds.), Dømt på forhånd (1st ed., pp. 47-65). København: Psykiatrifonden.

Blumer, H. (1969). Symbolic Interactionism: Perspective and Method (1st ed.). London: University of California Press.

Borba, C. P. C., DePadilla, L., McCarty, F. A., Von Esenwein, S. A., Druss, B. G., \& Sterk, C. E. (2012). A Qualitative Study Examining the Perceived Barriers and Facilitators to Medical Healthcare Services among Women with a Serious Mental Illness. Women's Health Issues, 22, 217-224. https://doi.org/10.1016/j.whi.2011.10.001

Bryant, A., \& Charmaz, K. (2014). Grounded Theory in Historical Perspective : An Epistemological Account. In the SAGE Handbook of Grounded Theory (pp. 31-57).

Charmaz, K. (2001). Qualitative Interview and Grounded Theory Analysis. In J. F. Gubrium \& J. A. Holstein (Eds.), Handbook of Interview Research: Context and Method (1st ed., pp. 675-695). Thousand Oaks: SAGE Publications. https://doi.org/10.4135/9781412973588.n39

Coffey, A., \& Atkinson, P. (1996). Making Sense of Qualitative Data: Complementary Research Strategies. Thousand Oaks: Sage Publications.

Creswell, J. W. (2013). Qualitative Inquiry and Research Design. Choosing among Five Approaches (3rd ed.). Thousand Oaks: SAGE Publications.

Crotty, M. (1998). The Foundation of Social Research. Meaning and Perspective in the Research Process (1st ed.). London: Sage Publications.

De Hert, M., Cohen, D., Bobes, J., Cetkovich-Bakmas, M., Leucht, S., Ndetei, D. M., \& Correll, C. U. (2011). Physical Illness in Patients with Severe Mental Disorders. II. Barriers to Care, Monitoring and Treatment Guidelines, Plus Recommendations at the System and Individual Level. World Psychiatry: Official Journal of the World Psychiatric Association (WPA), 10, 138-151.

https://doi.org/10.1002/j.2051-5545.2011.tb00036.x

Ewart, S. B., Bocking, J., Happell, B., Platania-Phung, C., \& Stanton, R. (2016). Mental Health Consumer Experiences and Strategies When Seeking Physical Health Care: A Focus Group Study. Global Qualitative Nursing Research, 3. https://doi.org/10.1177/2333393616631679

Flick, U. (2009). An Introduction to Qualitative Research (4th ed.). London: SAGE Pub- 
lications Ltd.

Flyvbjerg, B. (2011). Case Study. In N. K. Denzin \& Y. S. Lincoln (Eds.), The Sage Handbook of Qualitative Research (1st ed., pp. 301-316). Thousand Oaks: SAGE Publications.

Goffman, E. (1963). Stigma. Notes on the Management of Spoiled Identity. London: Penguin Books.

Goffman, E. (2005). Interaction Ritual: Essays in Face-to-Face Behaviour. American Sociological Review, New Brunswick: Transaction Publishers.

Hardy, S., Deane, K., \& Gray, R. (2012). The Northampton Physical Health and Wellbeing Project: The Views of Patients with Severe Mental Illness about Their Physical Health Check. Mental Health in Family Medicine, 9, 233. https://www.ncbi.nlm.nih.gov/pmc/articles/PMC3721917/

Hassan, I., Mccabe, R., \& Priebe, S. (2007). Professional-Patient Communication in the Treatment of Mental Illness: A Review. Communication \& Medicine, 4, 141-152. https://doi.org/10.1515/CAM.2007.018

Horsfall, J., Cleary, M., \& Hunt, G. E. (2010). Stigma in Mental Health: Clients and Professionals. Issues in Mental Health Nursing, 31, 450-455. https://doi.org/10.3109/01612840903537167

Hospital, A. M., Hospital, A. M., Ong, L. M. L., de Haes, J. C. J. M., Hoos, A. M., \& Lammes, F. B. (1995). Doctor-Patient Communication: A Review of the Literature. Social Science \& Medicine, 40, 903-918. https://doi.org/10.1016/0277-9536(94)00155-M

Israel, M. (2015). Research Ethics and Integrity for Social Scientists: Beyond Regulatory Compliance (2nd ed.). London: SAGE Publications. https://doi.org/10.4135/9781473910096

Jacobsen, C. B., Martin, H. M., Andersen, S. L., Christensen, R. N., \& Bengtsson, S. (2010). Stigma og psykiske lidelser. København.

Kølbæk, P., Schiöth, E., Aagaard, J., \& Munk-Jørgensen, P. (2014). Follow-Up Interventions in Persons with Schizophrenia and Metabolic Syndrome. Australian \& New Zealand Journal of Psychiatry, 48, 1059-1060. https://doi.org/10.1177/0004867414553955

Lawrence, D., \& Kisely, S. (2010). Inequalities in Healthcare Provision for People with Severe Mental Illness. Journal of Psychopharmacology, 24, 61-68. https://doi.org/10.1177/1359786810382058

Lawrence, D., Hancock, K. J., \& Kisely, S. (2013). The Gap in Life Expectancy from Preventable Physical Illness in Psychiatric Patients in Western Australia: Retrospective Analysis of Population Based Registers. BMJ, 346, 1. https://doi.org/10.1136/bmj.f2539

Lester, H., Tritter, J. Q., \& Sorohan, H. (2005). Patients' and Health Professionals' Views on Primary Care for People with Serious Mental Illness: Focus Group Study. British Medical Journal, 330, 1122-1126. https://doi.org/10.1136/bmj.38440.418426.8F

Link, B. G., \& Phelan, J. C. (2001). Conceptualizing Stigma. Annual Review of Sociology, 27,363-385. https://doi.org/10.1146/annurev.soc.27.1.363

Mainz, J., Sloth, A., \& Kjølbye, M. (2014). De mange aktører og deres samarbejde. [The Many Actors and Their Cooperation.] In P Jørgensen, \& C. Thomsen (Eds.), Fysisk helbred blandt psykisk syge (1st ed., pp. 227-237). København: FADL’s forlag.

Maj, M. (2009). Physical Health Care in Persons with Severe Mental Illness: A Public Health and Ethical Priority. World Psychiatry, 8, 1-2. https://doi.org/10.1002/j.2051-5545.2009.tb00196.x 
Mik-Meyer, N., \& Järvinen, M. (2005). Indledning: Kvalitative metoder i et interaktionistisk perspektiv. In N. Mik-Meyer \& M. Järvinen (Eds.), Kvalitative metoder i et interaktionistisk perspektiv (1st ed., pp. 9-24). København: Hans Reitzels Forlag.

Ministeriet for Sundhed og Forebyggelse (2014). Bekendtgørelse af sundhedsloven. [EXecutive Order of the Health Law.] Copenhagen.

Mitchell, A., Malone, D., \& Doebbeling, C. (2009). Quality of Medical Care for People with and without Comorbid Mental Illness and Substance Misuse: Systematic Review of Comparative Studies. The British Journal of Psychiatry, 194, 491-499. https://doi.org/10.1192/bjp.bp.107.045732

Muntingh, A. D. T., van der, F.-C., Van Marwijk, H. W. J., Spinhoven, P., Assendelft, W. J. J., de Waal, M. W., Van Balkom, A. J. L. M. et al. (2009). Collaborative Stepped Care for Anxiety Disorders in Primary Care: Aims and Design of a Randomized Controlled Trial. BMC Health Services Research, 9, 159. https://doi.org/10.1186/1472-6963-9-159

Nordentoft, M., Wahlbeck, K., Hällgren, J., Westman, J., Ösby, U., Alinaghizadeh, H., Burne, T. et al. (2013). Excess Mortality, Causes of Death and Life Expectancy in 270,770 Patients with Recent Onset of Mental Disorders in Denmark, Finland and Sweden. PLoS ONE, 8, e55176. https://doi.org/10.1371/journal.pone.0055176

Pitman, A. L., Osborn, D. P. J., Wright, C. A., Nazareth, I., \& King, M. B. (2011). Cardiovascular Screening of People with Severe Mental Illness in England: Views of Service Users and Providers. Psychiatric Services, 62, 1338.

https://doi.org/10.1176/appi.ps.62.11.1338

Region Hovedstaden (2015). Sundhedsaftale 2015-2018. [Health Agreement 2015-2018.] Copenhagen.

https://www.regionh.dk/Sundhedsaftale/bilag-og-download/Documents/SamletSundhe dsaftale2015-2018.pdf

Roberts, S. H., \& Bailey, J. E. (2011). Incentives and Barriers to Lifestyle Interventions for People with Severe Mental Illness: A Narrative Synthesis of Quantitative, Qualitative and Mixed Methods Studies. Journal of Advanced Nursing, 67, 690-708. https://doi.org/10.1111/j.1365-2648.2010.05546.x

Robson, D., \& Gray, R. (2007). Serious Mental Illness and Physical Health Problems: A Discussion Paper. International Journal of Nursing Studies, 44, 457-466.

https://doi.org/10.1016/j.ijnurstu.2006.07.013

Shuel, F., White, J., Jones, M., \& Grey, R. (2010). Using the Serious Mental Illness Health Improvement Profile [HIP] to Identify Physical Problems in a Cohort of Community Patients: A Pragmatic Case Series Evaluation. International Journal of Nursing Studies, 47, 136-145. https://doi.org/10.1016/j.ijnurstu.2009.06.003

Sikker Psykiatri (2016). Projekt Sikker Psykiatri fortsætter til 2017. [Project Safe Psychiatry continues until 2017.]

http://www.sikkerpsykiatri.dk/nyheder/2016/maj/projekt-sikker-psykiatri-fortsaetter-ti $1-2017 /$

Silverman, J., \& Kinnersley, P. (2010). Doctors'non-Verbal Behaviour in Consultations: Look at the Patient before You Look at the Computer. British Journal of General Practice, 60, 76-78. https://doi.org/10.3399/bjgp10X482293

Smith, R. A. (2007). Language of the Lost: An Explication of Stigma Communication. Communication Theory, 17, 462-485. https://doi.org/10.1111/j.1468-2885.2007.00307.x

Smith, R. A., Quesnell, M., \& Zhu, X. (2016). Stigma and Health/Risk Communication. Oxford Res. Encycl. Commun., Oxford: Oxford University Press.

Sowers, W., Arbuckle, M., \& Shoyinka, S. (2016). Recommendations for Primary Care Provided by Psychiatrists. Community Mental Health Journal, 52, 379-386. 
https://doi.org/10.1007/s10597-015-9983-0

Sundhedsstyrelsen (2009). National Strategi for Psykiatri. [National Strategy for Psychiatry.] Copenhagen.

Thornicroft, G., Rose, D., \& Kassam, A. (2007). Discrimination in Health Care against People with Mental Illness. International Review of Psychiatry, 19, 113-122. https://doi.org/10.1080/09540260701278937

Tranter, S., Irvine, F., \& Collins, E. (2012). Innovations Aimed at Improving the Physical Health of the Seriously Mentally Ill: An Integrative Review. Journal of Clinical Nursing, 21, 1199-1214. https://doi.org/10.1111/j.1365-2702.2011.04020.x

Van Den Tillaart, S., Kurtz, D., \& Cash, P. (2009). Powerlessness, Marginalized Identity, and Silencing of Health Concerns: Voiced Realities of Women Living with a Mental Health Diagnosis. International Journal of Mental Health Nursing, 18, 153-163. https://doi.org/10.1111/j.1447-0349.2009.00599.x

van Hasselt, F. M., Thier, C. S. M., van Rijswijk, E., \& Loonen, A. J. M. (2014). Is Somatic Health Screening in Patients with Severe Mental Illness of Added Value? Perspectives in Psychiatric Care, 50, 186-192. https://doi.org/10.1111/ppc.12042

Vreeland, B. (2007). Bridging the Gap between Mental and Physical Health: A Multidisciplinary Approach. Journal of Clinical Psychiatry, 68, 26-33.

Wahl, O. F. (2012). Stigma as a Barrier to Recovery from Mental Illness. Trends in Cognitive Sciences, 16, 9-10. https://doi.org/10.1016/j.tics.2011.11.002

Wright, C. A., Osborn, D. P. J., Nazareth, I., \& King, M. B. (2006). Prevention of Coronary Heart Disease in People with Severe Mental Illnesses: A Qualitative Study of Patient and Professionals' Preferences for Care. BMC Psychiatry, 6, 16.

https://doi.org/10.1186/1471-244X-6-16

Yin, R. K. (2009). Case Study Research. Design and Methods (4th ed.). Thousand Oaks, CA: SAGE Publications, Inc.

Yin, R. K. (2016). Qualitative Research from Start to Finish (2nd ed.). New York, NY: Guilford Publications. 